Abstracta Iranica Abstracta Iranica

Revue bibliographique pour le domaine irano-aryen

Volume 34-35-36 | 2017

Comptes rendus des publications de 2011-2013

\title{
Dafna Langgut, Yuval Gadot, Naomi Porat, Oded Lipschits. Fossil pollen reveals the secrets of the Royal Persian Garden at Ramat Rahel, Jerusalem
}

\section{Sébastien Gondet}

\section{(2) OpenEdition \\ 1 Journals}

Édition électronique

URL : http://journals.openedition.org/abstractairanica/42113

DOI : 10.4000/abstractairanica.42113

ISSN : 1961-960X

\section{Éditeur :}

CNRS (UMR 7528 Mondes iraniens et indiens), Éditions de l'IFRI

\section{Référence électronique}

Sébastien Gondet, « Dafna Langgut, Yuval Gadot, Naomi Porat, Oded Lipschits. Fossil pollen reveals the secrets of the Royal Persian Garden at Ramat Rahel, Jerusalem », Abstracta Iranica [En ligne], Volume 34-35-36 | 2017, document 112, mis en ligne le 30 juillet 2017, consulté le 26 septembre 2020. URL : http://journals.openedition.org/abstractairanica/42113; DOI : https://doi.org/10.4000/ abstractairanica. 42113

Ce document a été généré automatiquement le 26 septembre 2020.

Tous droits réservés 


\title{
Dafna Langgut, Yuval Gadot, Naomi Porat, Oded Lipschits. Fossil pollen reveals the secrets of the Royal Persian Garden at Ramat Rahel, Jerusalem
}

\author{
Sébastien Gondet
}

\section{RÉFÉRENCE}

Dafna Langgut, Yuval Gadot, Naomi Porat, Oded Lipschits. « Fossil pollen reveals the secrets of the Royal Persian Garden at Ramat Rahel, Jerusalem ». Palynology, 37(1), 2013, p. 115-129.

1 Le site de Ramat Rahel se situe dans la banlieue sud de Jérusalem. Les fouilles sur ce site ont commencé dans les années 1960 et ont repris de manière plus systématique au cours des années 2000 (voir AI-Vol.32-33-Rub.3-2-2-n.97). Les résultats ont permis de mettre au jour un établissement palatial fondé à la fin VIII ${ }^{\mathrm{e}}$ s. av. J.-C. et abandonné au cours de la période hellénistique. Ce palais était environné d'un jardin parcouru de canaux souterrains et parsemé de plusieurs bassins.

2 Le présent article détaille les résultats d'une étude très originale menée sur les enduits d'un de ces bassins. Il s'agit d'une étude des pollens, qui ont été emprisonnés dans les différentes couches d'enduit au moment de leur séchage, combinée à des datations par thermoluminescence (OSL) de ces couches. Les résultats obtenus ont permis de restituer une partie de la flore cultivée dans le jardin au cours du IV ${ }^{\mathrm{e}}$ s., c'est-à-dire la période de transition achéménide/hellénistique. Les espèces halogènes, que l'on retrouve régulièrement dans les jardins plus tardifs, voisinent avec des espèces exogènes comme le noyer, très certainement importé du nord de l'Iran actuel, ou encore le citronnier, dont on possède ici probablement la plus ancienne attestation pour le Levant. Le palais de Ramat Rahel, qui à l'époque perse devait abriter le 
souverain local, était donc environné d'un jardin à la végétation luxuriante, où l'eau prenait une place importante et dans lequel était pratiquée l'arboriculture.

Parmi les résultats de cette étude importante, les analyses menées démontrent que la période achéménide a certainement été le témoin d'une importante circulation, dans l'empire, des espèces végétales et des pratiques agricoles qui leur sont associées. Il est à ce titre dommage que les AA. limitent leurs conclusions au seul Levant et n'initient pas des comparaisons avec d'autres régions de l'empire où jardins et pratiques agricoles achéménides ont fait et font toujours l'objet d'importantes recherches historiques et archéologiques (on pense surtout à l'ancienne province de Perse).

\section{AUTEURS}

\section{SÉBASTIEN GONDET}

UMR 5133 CNRS-Université de Lyon 